\title{
Comunicação financeira no ecossistema virtual: informalidade, polifonia e humor no canal Me poupe! no YouTube
}

Financial communication in the virtual ecosystem: informality, polyphony and humor in the "Me poupe!" channel

Comunicación financiera en el ecosistema virtual: Informalidad, polifonia y humor en el canal "Me Poupe!"

\section{Ana Maria Dantas de Maio}

- Doutora em Comunicação Social pela Universidade Metodista de São Paulo.

- Jornalista do Núcleo de Comunicação Organizacional da Embrapa Pecuária Sudeste (São Carlos-SP).

- E-mail:anamaio@uol.com.br

Marcelo Pereira da Silva

- Pós-doutor em Comunicação pela Universidade Estadual Paulista/FAAC.

- Docente permanente do Mestrado Interdisciplinar em "Linguagens, Mídia e Arte" e dos cursos de Relações Públicas, Jornalismo e Mídias Digitais da Pontifícia Universidade Católica de Campinas (PUC-Campinas).

- E-mail: marcelosilva_rp@hotmail.com 


\section{Resumo}

O ecossistema midiático digital tornou-se ribalta para a pesquisa em comunicação organizacional em virtude de transformações sociotécnicas, comunicativas e econômicas que alteram percepções e ressignificam cognições. Pela análise de discurso de tradição francesa, estudou-se o audiovisual "6 lições do coronavírus que eu nunca vou esquecer", do canal Me Poupe! Nele, Nathalia Arcuri subverte a linguagem tradicional da educação financeira, adotando discurso polifônico que constitui sentidos de generalização, informalidade e humor. Infere-se que o dispositivo de enunciação provoca coenunciadores a decifrá-lo.

PALAVRAS-CHAVE: COMUNICAÇÃO FINANCEIRA • COMUNICAÇÃO ORGANIZACIONAL・ECOSSISTEMA DIGITAL・DISCURSO • ME POUPE!.

\section{Abstract}

By catalyzing sociotechnical, communicational, and economic transformations that alter perceptions and resignify cognitions, the digital media ecosystem has become a stage for research on corporate communication. Based on the French tradition of discourse analysis, this study evaluates the discursive functioning of the audiovisual production entitled "6 lessons from the coronavirus that I will never forget", from the Me Poupe! YoutTube channel by Nathalia Arcuri. In subverting the traditional language of financial education and adopting a polyphonic discourse that constructs generalization, informality and humor, the analysis suggest that the enunciation device of the work at stake prompts spectators to decipher it.

KEYWORDS: FINANCIAL COMMUNICATION • CORPORATE COMMUNICATION • DIGITAL ECOSYSTEM・DISCOURSE • ME POUPE!.

\section{Resumen}

El ecosistema mediático digital es tema para los estudios en comunicación organizacional por las transformaciones sociotécnicas, comunicativas y económicas que cambian las percepciones y resignifican las cogniciones. Por el análisis de discurso de la escuela francesa se analizó el vídeo "6 lecciones del coronavírus que nunca voy a olvidarme", del canal Me Poupe! En él, Nathalia Arcuri subvierte el lenguaje tradicional de la educación financiera adoptando un discurso polifónico que constituye sentidos de generalización, informalidad y humor. Se infiere que el dispositivo de enunciación lleva a que los coenunciadores lo descifren. 


\section{INTRODUÇÃO}

0 ecossistema digital se constitui de redes de comunicação que envolvem linguagem simbólica, restrições culturais, relações de poder etc., e deve ser analisado como fenômeno social, antropológico, filosófico e comunicacional. 0 potencial de produção, difusão, trocas e compartilhamento de conteúdo, dados e informações, bem como a aptidão às conversações tipificam o habitar on-line.

Baseadas na dinâmica de produção e circulação de discursos, as redes virtuais fogem das limitações usuais da organização textual, da correspondência epistolar e das formas de textualidade orgânica, de acordo com Maingueneau (2015), sem ritos de abertura e fechamento como ocorrem nas interações tradicionais. Assim, o ecossistema digital comunga um capital social cuja natureza implica questões de confiança, reciprocidade, consenso, cooperação e partilha (Santaella, 2010).

Considera-se, conforme Recuero (2014a), que as idiossincrasias da conversação na web são fruto dos usos que os sujeitos fazem da tecnologia, não das ferramentas per si. Estas interações interpretam e reconstroem a cultura, as relações e as trocas simbólicas entre os sujeitos. Empresta-se de Barichello et al. (2013) o conceito de entidade para classificar os diferentes atores que atuam no ecossistema virtual, pois remete, a mesmo tempo, a individualidades - artistas, políticos, jornalistas, economistas, pessoas físicas - e a coletividades - organizações públicas, privadas e do terceiro setor.

Esta conceituação se torna relevante para o objetivo deste estudo: investigar o fenômeno da popularização de um projeto de educação financeira formatado para o ambiente digital - mas não restrito a ele - por meio da análise de discurso da escola francesa, focando na produção audiovisual intitulada "6 lições do coronavírus que eu nunca vou esquecer", do canal no YouTube Me poupe!. Considera-se que, entre 2014 e 2019, o consumo de vídeos nas redes no Brasil aumentou 165\%, segundo o sexto levantamento Video Viewers realizado pelo Instituto Provokers e encomendado pelo Google. "Entre os participantes da pesquisa, seis em cada dez decidiram buscar melhorias na carreira depois de assistir a materiais on-line" (Andrion, 2019), fato que evidencia a pertinência teórica, metodológica e analítica deste artigo.

\section{CONTEXTUALIZANDO O OBJETO: ME POUPE! E NATHALIA ACURI}

Concebido pela jornalista Nathalia Arcuri em 2015, o canal Me Poupe!, na rede social digital YouTube, reúne, em maio de 2021, mais de seis milhões de seguidores (internautas que se registraram para receber notificações de conteúdo). A profissional se apropria de um ethos "caseiro" em seus vídeos e de uma linguagem informal, de fácil entendimento para diferentes classes sociais e níveis de escolaridade.

Nathalia se apresenta como educadora em um canal de entretenimento financeiro. Produz conteúdos que procuram orientar seus seguidores sobre formas de enriquecer. Os materiais incluem desde dicas para gastar menos e ganhar mais até orientações sobre aplicações. A autopromoção é uma característica do funcionamento discursivo expressa nos conteúdos verbal e visual, e a enunciação se reveste de apelo argumentativo, com o uso de recursos da polifonia.

O Me Poupe! busca inovar no formato e na linguagem, favorecendo uma relação de intimidade e a negociação de sentidos com seus coenunciadores. 0 vídeo de 11 minutos e 20 segundos selecionado para a análise foi produzido e divulgado durante a pandemia de coronavírus, em 27 de abril de 2020, e apresenta lições que a jornalista afirma ter aprendido com as dificuldades 
estabelecidas pelo distanciamento social. Até o fechamento deste artigo, em maio de 2021, a produção audiovisual acumulava 447.517 mil visualizações, 3.135 comentários¹, 61 mil curtidas e 784 dislikes.

No mesmo mês da publicação, a Confederação Nacional do Comércio de Bens, Serviços e Turismo (CNC) noticiou que o número de famílias endividadas durante a pandemia atingiu um recorde: 66,6\% (Medeiros; Sena, 2020).

Outro levantamento feito pelo Serviço de Proteção ao Crédito (SPC) e pela Confederação Nacional dos Diretores Lojistas (CNDL), em 2018, aponta que 36\% dos brasileiros não controlam as próprias finanças e, dos que o fazem, $62 \%$ sentem alguma dificuldade (Cresce..., 2019). A proposta do Me Poupe! encontra, assim, um terreno fértil para explorar, oferecendo apoio ao seu público digital, já que ensinar brasileiros a controlar as finanças é um dos objetivos declarados pela youtuber no canal.

\section{UM UNIVERSO COMPLEXO: O ECOSSISTEMA DIGITAL}

A ecologia da comunicação apresenta um cenário epistemológico inovador para a pesquisa, renovando-se por meio de categorias oriundas das transformações no sistema midiático virtual (Barichello etal., 2013). Esta consideração aponta para o pensamento de Scolari (2010), lançando luz aos pressupostos do conceito de ecologia, a saber: 1. Os meios de comunicação constituem um entorno que muda percepções e cognições; 2 . Os meios são as espécies que vivem em um ecossistema e estabelecem relações entre si e com os sujeitos do seu derredor, em um fluxo multilateral fluido e complexo.

O habitar on-line produz uma ecologia dos novos meios na qual entidades, sujeitos e públicos dialogam e duelam, conversam e pelejam, interagem e "viram" a face, participam e criticam, organizam protestos e acompanham ações políticas e públicas (Recuero, 2014a). A metáfora da ecologia da comunicação representa sua complexidade e as possibilidades de novos negócios e táticas de monetização.

De acordo com Di Felice (2017, p.33), a ecologia da comunicação surge como uma "arquitetura comunicante capaz de dar forma às interações entre os membros humanos e não humanos, os fluxos informativos e as territorialidades", produzindo modalidades de interação e dinâmicas informativas próprias. Esta posição aponta as redes como criadoras de espaço e formas de habitar, as quais estabelecem limites, desafios e oportunidades, haja vista recompensarem os desejos intrínsecos de engajamento, participação e compartilhamento (Shirky, 2011).

A interface do ecossistema on-line com o usuário vem alterando os modos de organização, identidade, subjetivação e conversação. Com os meios de comunicação de massa, os sujeitos estavam tecnologicamente alijados da participação no processo comunicativo, "relegados à condição de excluídos do processo de construção da mensagem que chegava" (Di Felice, 2012, p.157). As fórmulas da sociedade de massa não conseguem explicar o dinamismo das interações sociais contemporâneas, assim as entidades são chamadas ao exercício de um recente papel no sistema sociotécnico.

As redes da internet se apresentam como emergente ato comunicativo, levando a uma redefinição e reposicionamento da noção de ação comunicativa e seu impacto na estrutura social. Recuero (2014b) defende que as redes on-line afirmam a relevância do capital social na sua manutenção, mas sem aprofundar os laços dessas redes. Primo (2016), por sua vez, acredita que as interações mediadas pela tecnologia não podem pensar a produção e a recepção como extremos que se negam, pois isso dificulta o entendimento dos processos midiáticos.

1 Considera-se a relevância dos comentários dos usuários, mas o foco desta pesquisa reside no discurso do canal encarnado na apresentadora Nathalia Arcuri, não na interatividade que flui por meio dele. 
Os sujeitos contemporâneos são, ao mesmo tempo, para Lipovetsky e Charles (2004, p. 28), mais informados e mais desestruturados, "mais adultos e mais instáveis, [...] mais abertos e mais influenciáveis, mais críticos e mais superficiais, mais céticos e menos profundos". Habitam uma sociedade midiatizada cuja lógica perpassa as ambiências como gás, "despolarizando o polo emissor, hibridizando instâncias de emissão e recepção" (Barichello etal., 2013).

Corrêa (2016) afiança que os papéis e as competências dos participantes do ecossistema virtual são quase equivalentes e que as (re)ações dos públicos passaram a demandar a construção de narrativas inovadoras, gestão de relacionamentos, reorganização das estruturas comunicativas e a consciência da perda de controle dos fluxos informativos, instigando as organizações a uma perspectiva mais inclusiva, aberta e sensível às exigências dos públicos. Os diálogos, na simultaneidade do ecossistema virtual, são formatados em modelos mais simples e diretos, semiprontos para a degustação.

A linguagem on-line constitui um sujeito emergente e estimula a participação. Essas novas formas de se comunicar e, ao mesmo tempo, consumir e produzir conteúdo, revelam discursos em movimento, cuja natureza pode fomentar cooperação, produzindo capital social relevante para se (re)pensar a tecnologia discursiva e os sujeitos que nela atuam.

\section{DISCURSO E SUBJETIVIDADE NO ECOSSISTEMA DIGITAL}

O campo discursivo possibilita a articulação entre o extralinguístico e o linguístico ao entender que a constituição das significações está na relação entre as condições sócio-históricas, culturais e o texto. Nesta direção, ao sistema da língua se imprimem as marcas ideológicas que constituem diferentes gêneros de discurso.

É na e pela linguagem que a ideologia se representa, articulam-se e defrontam-se agentes coletivos na forma de sujeitos, e se legitimam relações intersubjetivas que se dão por meio da língua e são permeadas por efeitos de sentido que não são determinados pela esfera da emissão, já que decodificados e ressemantizados pela recepção (Gonçalves; Silva, 2015).

Na subjetividade reside a capacidade de o locutor se propor como sujeito do seu discurso, fundando-se no exercício da língua, já que toda enunciação é, explícita ou implicitamente, uma alocução, quando eu e tu são protagonistas do processo enunciativo. A subjetividade se define como a vida interior, as opções mais pessoais marcadas por um ethos em que a socialidade assume um tom caracteristicamente marcante e que constitui o sujeito.

O ecossistema midiático não se fecha em si mesmo, não compreende um espaço centrado em um único sujeito, proposta, ou uma só entidade e segmento de atuação. As ambiências digitais constroem conexões entre os sujeitos, constituindo "um leito propício para a fertilização de novas formas de subjetivação" (Santaella, 2010, p.285). 0 homem é um sujeito universal, fruto das relações sociais, agora mediadas pelo mundo técnico e tecnológico no qual os discursos se constituem, produzem sentidos, circulam, são consumidos, refutados e ressemantizados.

\section{TRAÇADO METODOLÓGICO}

A análise de discurso (AD) da escola francesa é a metodologia escolhida para conectar a enunciação do canal Me Poupe! às demandas dos sujeitos no ecossistema digital. Reconhecidamente, o processo de midiatização social realoca as práticas comunicacionais, levando o coenunciador a migrar das categorias de "leitor contemplativo" e "leitor movente" para a de "leitor imersivo": 
Trata-se da emergente forma de leitura que surge com os novos espaços incorpóreos da virtualidade, que navega através de fluxos informacionais voláteis, líquidos e híbridos - sonoros, visuais e textuais - próprios da hipermídia. As diferentes potencialidades de movimento, a multiplicidade de nós e a profusão de imagens alteram por completo a linearidade da leitura, além das possibilidades de interação com as próprias mídias. (Oliveira, 2011, p.134)

A AD conforma um arcabouço teórico-metodológico que conecta o texto e o contexto. Permite avaliar componentes linguísticos e extralinguísticos que produzem sentidos no ato de enunciação e atribuem sentidos no exercício de coenunciação. Para Orlandi (2012, p.19), "a finalidade do analista de discurso não é interpretar, mas compreender como um texto funciona, ou seja, como um texto produz sentidos".

Nesse sentido, foi selecionado o vídeo "6 lições do coronavírus que eu nunca vou esquecer", do canal Me Poupe!", de modo intencional. 0 propósito reside na busca de um conteúdo representativo do projeto de educação financeira delineado pela youtuber Nathalia Arcuri. A opção por um material contextualizado na pandemia de Covid-19 se explica pelo esforço que a academia vem mobilizando para mapear os processos comunicacionais no período de calamidade pública pelo qual o país passa.

Além da fundamentação teórica sobre o ecossistema digital, são incorporados neste estudo conceitos que ancoram a análise discursiva do vídeo, como a polifonia revestida por recursos de gestualidade, discurso direto, generalização, ironia e argumentação, os quais caracterizam o funcionamento discursivo do Me Poupe!

\section{CENA ENUNCIATIVA: INTIMIDADE, AUTOPROMOÇÃO E EFEITOS ESPECIAIS}

Nathalia Arcuri lançou o canal Me Poupe! em 19 de fevereiro de 2015 e, em maio de 2021, acumulava 376 milhões de visualizações. A jornalista atuou anteriormente nos canais de TV abertos SBT e Record.

Sua experiência com o Jornalismo facilitou seu desenvolvimento em frente à câmera. Desde o início, ela conseguiu demonstrar descontração e nenhum nervosismo. Essa segurança foi um fator propulsor para o crescimento do canal "Me Poupe!". Ao contrário da televisão, o canal da Nathalia é muito descontraído, ela fala de um assunto considerado difícil/chato com muita facilidade e explica de forma que os inscritos entendam. (Santana, 2018, p.20)

Responsável não apenas pela apresentação dos vídeos, mas pela produção, Nathalia demonstra conhecimento técnico para imprimir qualidade ao som, à imagem, ao cenário, ao figurino e à edição. No vídeo analisado, a personagem jovem, bonita, maquiada, unhas esmaltadas, cabelo preso, usando brincos discretos e anéis chamativos aparece o tempo todo no centro da tela, olhando diretamente para a câmera - que na referência da enunciação representa o interlocutor. A dinâmica da narrativa é impulsionada por mudanças na entonação e ritmo da fala, bem como pelo uso intensivo de gestos e expressões faciais (comunicação não verbal).

O cenário da gravação é, provavelmente, seu quarto, o que reforça a referência de intimidade da enunciação. É possível visualizar luminárias, livros, revistas e enfeites sobre as mesas de cabeceira. A composição de cores em tons predominantemente cinzas em contraste com o branco da cabeceira da cama e do tecido sobre o colchão sugere uma combinação sóbria com sua roupa preta e o cabelo castanho. 
O figurino da apresentadora - blusa com ombros vazados e parte da barriga à mostra - confere à locutora um aspecto jovial e despojado. No making of em preto e branco, no final, Nathalia mostra as pernas simulando uma ginástica, o que reforça 0 caráter informal do discurso audiovisual e seu estilo bem "à vontade" diante do público².

A narrativa é acelerada por recursos de edição, como efeitos sonoros e visuais. 0 editor aplica sobre a imagem ao menos 14 gifs, ícones, desenhos e outros elementos animados; 32 legendas ilustrativas e descritivas; efeitos de transição; sons de notificações, de berros e até de um "pum" para ilustrar a legenda "shit happens"; distorções de voz e de imagem (rosto) para simular outro sujeito locutor.

Da televisão, Nathalia importou recursos tradicionais, como o título chamativo na tela, a vinheta, os créditos, o making of e a autopromoção. Na cena enunciativa em análise, a youtuber menciona o próprio canal dez vezes, além de impulsionar visualmente outros cinco vídeos no canto superior direito da tela. A autopropaganda é incorporada de forma sutil e, muitas vezes, passa despercebida. A promoção mais visível tem duração de 20 segundos e apresenta uma nova plataforma lançada pelo canal, o SOS Me Poupe! Neste caso, a divulgação é feita por voz e pela logomarca do serviço exposta na tela.

\section{JOGO POLIFÔNICO - NATHALIA X NATHALIA: QUEM FALA PARA QUEM?}

Embora responda pela locução e produção do enunciado, Nathalia Arcuri incorpora no vídeo um discurso polifônico que reúne outras vozes - e pontos de vista diferentes. É frequente ela se identificar com o pronome pessoal "eu", mas também recorre ao "nós" e "a gente" para exprimir um sujeito amplificado, vago e difuso (Maingueneau, 2013). Em dado momento, a fala descreve essa diferença e a jornalista avisa que o vídeo é introspectivo e revela "é uma opinião minha, Nathalia Arcuri, como entidade, não representa a opinião de empresa Me Poupe!".

Aos 3'18, a locutora interrompe o discurso mais caseiro e experimental para construir um ethos corporativo e "democrático": "sou a fundadora deste canal, sou a fundadora da empresa, mas pode ser que algumas pessoas da minha equipe discordem de mim. E aqui é assim: cada um tem o direito de pensar do jeito que quer pensar. E se você [coenunciador] pensa diferente, eu já te convido a deixar a sua opinião com argumentos aqui embaixo". A possibilidade de interagir, ainda que textualmente e por meio de figuras, tipifica o ecossistema virtual, já que amplifica o diálogo, as conversações, as trocas, o compartilhamento e a construção de subjetividades on-line (Di Felice, 2017; Gonçalves; Silva, 2015; Recuero, 2014a; Santaella, 2010; Shirky, 2011).

O "você", a quem a youtuber se dirige, é caracterizado logo no início do vídeo em "olá, meninos e meninas", saudação que ela padroniza em suas produções. Nathalia fala a um público notadamente jovem (não necessariamente em termos de idade), aberto e atento à questão de gênero. Ao convidar o coenunciador para o debate e reforçar o uso de ar-gu-men-tos [a fala é pausada, marcada com uma legenda grande e apontada com os dois dedos indicadores], a locutora seleciona interlocutores capazes de construir ideias articuladas, inibe opiniões vagas, descontextualizadas, belicosas e redefine com quem gostaria de dialogar - o ethos democrático, aqui, passa a ser limitado e questionável.

A terceira pessoa "ele/eles" também ganha espaço no enunciado em construções como "o pequeno vendedor", "essa pessoa", "ela", "pequenos empreendedores", "o governo" e outras. Nestes casos, a educadora se refere a um sujeito indeterminado e coletivo, usado com força argumentativa, e cabe ao coenunciador recorrer ao contexto para identificar seus modelos de referência (Charaudeau; Maingueneau, 2016; Maingueneau, 2013).

2 Making of é um recurso da produção audiovisual que mostra os bastidores da gravação. Geralmente é apresentado no final do vídeo.

3 Traduzido no próprio vídeo por Nathalia como "merdas acontecem". 
O discurso em análise também é rico em pronomes indefinidos, como "muitos", "ninguém", "todo mundo", "um monte", "as pessoas" etc. 0 uso de generalizações, na AD, permite ao locutor "produzir um enunciado que se apresenta como incontestável", de acordo com Charaudeau e Maingueneau (2016, p.248). Trata-se de um artifício argumentativo que visa convencer e intervir nas crenças do coenunciador, produzindo um efeito de verdade, haja vista basear-se na convicção, apresentando um saber de opinião que emerge da subjetividade do sujeito e sua relação com o mundo (Charaudeau, 2006).

A própria locutora assume outros papéis no funcionamento do discurso polifônico. Nathalia é "eu", "você" e "ele" na mesma peça. Quando a voz e o rosto aparecem de forma distorcida, o enunciador apresenta uma outra personagem identificada com o "você" ou pelo pronome reflexivo "se". Este mecanismo enunciativo é utilizado em falas como "Que porra é essa de índice Nikkei?" (2'34), "nossa, que absurdo, é claro que é [coisa] de gente rica" (5'59), "comenta [você] aqui embaixo: eu ajudei, Nath" (9'38).

A narradora se transforma em terceira pessoa ao dizer: "A Nath [ela] quer saber" (10'50). E também em duas situações em que encarna dois personagens: um economista tradicional e uma comissária de bordo. No primeiro caso, a gestualidade, os óculos desenhados sobre o olho esquerdo, a voz mais grossa e a expressão facial ironizam "um monte de entendido por aí", pseudoconcorrentes que tentam explicar economia do modo convencional: "Não, já atingiu o patamar porque atingiu a base, e daqui vai subir e tá na hora de comprar..." (5'25). No caso da aeromoça, rapidamente atualizada para "comissária de voo", Nathalia utiliza a analogia para simplificar a forma como os coenunciadores devem se comportar com o dinheiro durante a crise. A locutora não recorre a pronomes pessoais ou reflexivos, mas adota a mesma enunciação de comissários sobre o uso de máscaras em caso de despressurização (9'04).

Esta estrutura polifônica remete à comédia stand-up, shows feitos ao vivo, em geral, por apenas um humorista. A leveza que a educadora financeira busca caracteriza-se como técnica para estabelecer o diálogo popularesco com seu público. Para compor os diálogos de Nathalia com ela mesma, a locutora utiliza o discurso direto (DD).

Mesmo quando o DD relata falas consideradas como realmente proferidas, trata-se apenas de uma encenação visando criar um efeito de autenticidade, de uma espécie de imitação. De toda maneira, não há como comparar uma ocorrência de fala efetiva (com, no oral, determinada entonação, gestos, um auditório que reage...) e um enunciado citado entre aspas em contexto totalmente diverso. (Maingueneau, 2013, p.182)

Para Maingueneau (2013), por mais que seja fiel, o discurso direto não pode ser considerado objetivo, porque o fragmento selecionado é, de uma forma ou de outra, marcado pelo novo enunciador. É por meio do discurso direto que Nathalia define atos de fala e demarca a fronteira que a diferencia do discurso citado. 0 próprio coenunciador passa a se enxergar como parte da produção de sentidos. São enunciações que se encaixam e estabelecem o funcionamento do discurso.

No caso da ironia ao economista padrão, a youtuber emprega o DD para se legitimar como uma voz diferente, mais contemporânea e conectada com a juventude e públicos mais leigos. O uso da ironia se repete no enunciado: "se você não consegue entender nada disso, agradeça aos anos de governo que tivemos até agora e que não deram isso pra gente" (2'50). A ironia, na AD, segundo Maingueneau (2013), é empregada no sentido de desqualificar um sujeito - individual ou coletivo - e supervalorizar a própria enunciação.

Classifica-se tal fenômeno como um caso de polifonia, uma vez que esse tipo de enunciação pode ser analisado como uma espécie de encenação em que o enunciador expressa com suas palavras a voz de uma personagem ridícula que falasse seriamente e do qual ele se distancia, pela entonação e pela mímica, no instante mesmo em que lhe dá a palavra. (Maingueneau, 2013, p.222)

Há menos de uma década, seria impensável a prática de uma comunicação financeira que mesclasse na mesma mensagem audiovisual dois estilos antagônicos de linguagem: os famosos jargões econômicos, apelidados pelo público leigo de 
"economês" (como juros compostos, índice Nikkei, spread, bolsa de valores, alta do dólar, reserva de emergência, circuit breaker, score etc.) e um vocabulário popular que cria uma identificação imediata com o cidadão comum, coenunciador do canal ("lascado", "se ferra", "sem um puto pra viver", "merdas acontecem", "não tirou a bunda da cadeira", "na minha casa com o sutiã aparecendo", "tá torto esse bagulho", "que porra é essa?"). Estes elementos constituem a cena da enunciação, do enunciador e seu dispositivo discursivo, corroborando a informalidade, a gestualidade e os esforços do sujeito em tecer fios de sentido que gerem engajamento, interação, compreensão e interesse por temas tão distantes da cotidianidade do brasileiro, como economia e finanças.

Ao estudar o canal Me Poupe!, Moraes observou os dispositivos de enunciação que tornam possível a emergência de discursos que legitimam a imagem da "musa das finanças". Moraes (2019, p.15) destaca que o ethos discursivo de Nathalia Arcuri é "bem-humorado, enfrenta suas paixões e caminha na direção de seus propósitos". A análise revela uma locutora que se fortalece na busca de significação e que, com base no ethos de si mesma, pode refletir e inspirar outras pessoas.

0 interlocutor do vídeo "6 lições do coronavírus que eu nunca vou esquecer" se identifica e atribui sentido a mensagens muito próximas de seu cotidiano durante a pandemia, como as menções às mulheres que têm sido mais espancadas dentro de casa, pequenas empresas quebrando, críticas ao estado por ainda investir muito pouco em educação, a prática de tomar dinheiro emprestado, a solidariedade do brasileiro, o carro que vai quebrar, o filho que vai precisar comprar material escolar, remédio ou ir ao médico etc. Nathalia constrói um diálogo com seus destinatários ao apresentar-lhes conceitos de economia e finanças no escopo da vida como ela lhe parece ser, em um ecossistema no qual as textualidades fluem de modo orgânico (Maingueneau, 2015), sem ritos de abertura e fechamento.

Na esteira de Recuero (2014a), considera-se que as idiossincrasias da conversação na web são fruto dos usos e sentidos que os sujeitos fazem da tecnologia. Assim, as emergentes entidades que surgem no ecossistema virtual produzem conteúdos relevantes para públicos on-line que podem se tornar seguidores dos canais e potencializar o processo de monetização (o que ajuda a explicar o empenho na autopromoção). Sujeitos como Nathalia Arcuri conquistam espaço na multiplicidade de oportunidades de vocalização polifônica do digital, potencializando novas formas de negócio, de inovação e de lucratividade.

0 canal Me poupe! se eleva graças aos processos de subjetivação decorrentes das tecnologias discursivas e seus dispositivos técnicos, criando bricolagens da realidade investidas de informalidade, baseadas na produção de informações que geram sensibilidade, pertencimento e planejamento diante de um cenário no qual afloram demandas sanitárias, sociais, econômicas e financeiras.

\section{CONSIDERAÇÕES FINAIS}

No ecossistema digital, as entidades e organizações precisam buscar um novo tom, longe apenas das vendas e da lucratividade, rumando a uma conversação diuturna e um aprendizado constante com seus públicos de relacionamento, pois estes descobriram no potencial da internet formas de agrupar interesses, ganhar adeptos a uma ideia ou a uma crítica, colocando, frequentemente, as marcas na berlinda.

As redes sociais virtuais são sistemas complexos e qualquer análise que busque estabilizá-las para compreendê-las não será suficiente para capturar sua natureza caleidoscópica, haja vista a dimensão dos sentidos transcender as bases materiais, a superfície visível do objeto investigado. 0 habitar on-line acolhe estilos, subjetividades e discursos diversos. 0 modelo despojado e informal de ensinar economia a um público difuso e heterogêneo se posiciona como um case relevante para os estudos da comunicação financeira no contexto de ampliação do ecossistema digital. 
Para atingir esse status, a enunciadora precisou adaptar seu conhecimento da mídia tradicional (TV) e incorporar elementos da linguagem do universo virtual. Sob a proposta de educar financeiramente seus públicos, o Me Poupe! se apropria do discurso argumentativo e busca influenciar opiniões, hábitos, atitudes e comportamentos, produzindo novas formas de subjetividade.

Técnicas linguísticas adotadas pela apresentadora Nathalia Arcuri favorecem o reconhecimento mútuo com seus coenunciadores, que encontram no formato e no conteúdo do canal um material palatável, acessível e atraente. A introdução de personagens fictícios, da ironia, da gestualidade, da informalidade e da analogia no discurso incrementa a interface do enunciado e favorece a construção de uma relação íntima com o destinatário, em um tempo e uma história que não são externos aos sentidos, visto que a enunciação e os sentidos em si mesmo são históricos.

A análise de discurso alicerça este artigo lançando luz sobre a imbricação de uma representação da realidade e de uma atividade enunciativa construída por meio da transição do economês para o " shit happens", que representa não apenas um ajuste de linguagem, mas um fenômeno de reestruturação das subjetividades, da cultura, das enunciações e das trocas simbólicas na sociedade midiatizada. Inserida no ecossistema digital, Nathalia parece transpor 0 abismo que afastava 0 brasileiro do universo da educação financeira. De graça.

\section{REFERÊNCIAS}

6 LIÇÕES do coronavírus que eu nunca vou esquecer. [S.l., s.n.], 2020. 1 vídeo (11min). Publicado pelo canal Me Poupe! Disponível em: https://www.youtube.com/watch?v=rtL2txCsAYE. Acesso em: 29 maio 2020.

ANDRION, Roseli. Consumo de vídeo online cresce 165\% no Brasil nos últimos 5 anos. Olhar Digital, São Paulo, 25 set. 2019. Disponível em: https://olhardigital.com.br/noticia/consumo-de-video-online-cresce-165-no-brasil-nos-ultimos-5-anos/90726. Acesso em: 9 mar. 2020.

BARICHELLO, Eugênia M. da Rocha; STASIAK, Daiana; SCHEID, Daiane; FLORES, Ana Cássia Pandolfo; MACHADO, Jones. Estendendo as práticas de relações públicas sob a perspectiva teórica da ecologia das mídias. In: RUBLESCKI, Anelise; BARICHELLO, Eugenia Mariano da Rocha (org.). Ecologia da mídia. Santa Maria: Facos-UFSM, 2013. p.129-154.

CHARAUDEAU, Patrick; MAINGUENEAU, Dominique. Dicionário de análise do discurso. 3.ed. 2reimp. São Paulo: Contexto, 2016.

CORRÊA, Elisabeth Saad. A comunicação na sociedade digitalizada: desafios para as organizações contemporâneas. In: KUNSCH, Margarida (org.). Comunicação organizacional estratégica: aportes conceituais e aplicados. São Paulo: Summus, 2016. p.59-76.

CRESCE para 63\% o número de consumidores que controlam suas finanças, revelam CNDL/SPC Brasil e Banco Central. SPC Brasil, São Paulo, 23 jan. 2019. Disponível em: https://www.spcbrasil.org.br/pesquisas/pesquisa/5873. Acesso em: 25 jun. 2020.

DI FELICE, Massimo. Auréola digital: a crise dos pontos de vista centrais e o fim do direito exclusivo da edição das informações. In: MARCHIORI, Marlene; OLIVEIRA, Ivone de Lourdes (org.). Redes sociais, comunicação e organizações. São Caetano do Sul: Difusão, 2012. p.147-166. 
GONÇALVES, Elizabeth Moraes; SILVA, Marcelo da. A comunicação organizacional em tempo de redes sociais digitais. In: BUENO, Wilson da Costa (org.). Estratégias de comunicação nas mídias sociais. Barueri: Manole, 2015. p.69-85.

LIPOVETSKY, Gilles; CHARLES, Sébastien. Os tempos hipermodernos. São Paulo: Barcarolla, 2004.

MAINGUENEAU, Dominique. Análise de textos de comunicação. 6.ed. São Paulo: Cortez, 2013.

MAINGUENEAU, Dominique. Discurso e análise do discurso. São Paulo: Parábola, 2015.

MEDEIROS, Israel; SENA, Jailson R. Pesquisa da CNC aponta que endividamento das famílias bate recorde em 2020. Correio Braziliense, Brasília, DF, 15abr.2020. Disponível em: https://www.correiobraziliense.com.br/app/noticia/economia/2020/04/ 15/internas_economia,844706/pesquisa-da-cnc-aponta-que-endividamento-das-familias-bate-recorde-em.shtml. Acesso em: 29 jun. 2020.

MORAES, Érica de. Ethos da riqueza: caráter e corporalidade da "musa das finanças", Nathalia Arcuri. Caderno de Estudos Linguísticos, Campinas, v.61, p.1-17, 2019. doi:10.20396/cel.v61i0.8654838.

OLIVEIRA, José Aparecido. Novas práticas de leitura na linguagem do ciberespaço. In: GONÇALVES, Elizabeth Moraes (org.). Estudos de comunicação e linguagem: múltiplas experiências. São Caetano do Sul: Virgo, 2011. p.127-136.

ORLANDI, Eni Puccinelli. Discurso e texto: formulação e circulação dos sentidos. 4.ed. Campinas: Pontes, 2012.

PRIMO, Alex. Interações mediadas e remediadas: controvérsias entre as utopias da cibercultura e a grande indústria midiática. In: PRIMO, Alex (org.). Interações em rede. Porto Alegre: Sulina, 2016. p.13-32.

RECUERO, Raquel. A conversação em rede: comunicação mediada pelo computador e redes sociais na internet. Porto Alegre: Sulina, 2014a.

RECUERO, Raquel. Redes sociais na Internet. Porto Alegre: Sulina, 2014b.

SANTAELLA, Lucia. A ecologia pluralista da comunicação: conectividade, mobilidade ubiquidade. São Paulo: Paulus, 2010.

SANTANA, Nicole Sales. Produção independente: a migração de jornalistas para o YouTube. 2018. Trabalho de Conclusão de Curso (Bacharelado em Comunicação Social) - Centro Universitário do Sul de Minas, Varginha, 2018.

SCOLARI, Carlos A. Ecología de los medios. Mapa de un nicho teórico. Quaderns del CAC, v.13, n.1, p.17-25, 2010.

SHIRKY, Clay. A cultura da participação: criatividade e generosidade no mundo conectado. Rio de Janeiro: Zahar, 2011.

Artigo recebido em 30.06.2020 e aprovado em 03.05.2021. 